\title{
Capsazepine prolongation of the duration of lidocaine block of sensory transmission in mice may be mediated by modulation of HCN channel currents
}

\author{
Wenling Zhao ${ }^{\text {Equal first author, } 1,2}$, Peng Liang Equal first author, 1,2 , Jin Liu ${ }^{1,2}$, Huan Li $^{1}$, Daqing Liao ${ }^{1}$, Xiangdong Chen ${ }^{3}$, Qian Li \\ Corresp., 1, 2 , Cheng Zhou ${ }^{\text {Corresp. 1, } 2}$ \\ ${ }^{1}$ Laboratory of Anesthesia \& Critical Care Medicine, Translational Neuroscience Center, West China Hospital of Sichuan University, Chengdu, Sichuan, \\ China \\ 2 Department of Anesthesiology, West China Hospital of Sichuan University, Chengdu, Sichuan, China \\ 3 Department of Anesthesiology, Union Hospital of Tongji Medical College, Huazhong University of Science and Technology, Wuhan, Hubei, China \\ Corresponding Authors: Qian Li, Cheng Zhou \\ Email address: hxliqian@foxmail.com, zhouc@163.com
}

Background and Objectives: Hyperpolarization-activation cyclic nucleotide-gated (HCN) channels contribute to the effects of lidocaine. Capsazepine (CPZ), a competitive inhibitor of capsaicin of transient receptor potential vanilloid-1 (TRPV-1) channel, has also been found to inhibit HCN channel currents $\left(I_{h}\right)$. This study was designed to investigate whether CPZ could prolong durations of lidocaine in regional anesthesia.

Methods: Mouse HCN1 and HCN2 channels were expressed in HEK 293 cells. The effect of CPZ on $I_{\mathrm{h}}$ was measured by whole-cell patch-clamping recording. Sciatic nerve block model in mice was used for the study in vivo. The mice were randomly divided into 7 groups, respectively receiving lidocaine, CPZ, ZD7288 (HCN channel blocker), CPZ + lidocaine, ZD7288 + lidocaine, ZD7288 + CPZ + lidocaine, forskolin (an activator of adenylyl cyclase) + CPZ + lidocaine. Regional anesthetic durations of lidocaine were determined. Voltage-gated sodium channel currents $\left(I_{\mathrm{Na}}\right)$ and $I_{\mathrm{h}}$ were recorded in dorsal root ganglion (DRG) neurons of mice. The effects of CPZ on $I_{\mathrm{Na}}$ and $I_{\mathrm{h}}$ with or without CAMP were assessed. Isolated mice sciatic nerve was prepared to evaluate the effect of CPZ on the compound action potentials (CAP).

Results: CPZ non-selectively inhibited transfected mHCN1 and mHCN2 channel currents in HEK 293 cells. In sciatic nerve block in vivo, compared to lidocaine alone, adding CPZ extended the durations of lidocaine for noxious sensory block ( $35.1 \pm 3.3 \mathrm{vs}$. $20.3 \pm 1.7 \mathrm{~min}$ ), tactile sensory block ( $25.5 \pm 4.4$ vs. $20.0 \pm 3.7 \mathrm{~min})$, thermal sensory block (39.6 \pm 6.6 vs. $26.8 \pm 5.5 \mathrm{~min})$, and motor function block (28.6 \pm 4.1 vs. $20.9 \pm 4.2 \mathrm{~min}$ ). Duration of thermal sensory block was longer in CPZ + lidocaine group than that of ZD7288 + lidocaine group ( $39.6 \pm 6.6$ vs. $33.4 \pm 4.5 \mathrm{~min}$ ). Forskolin reversed the prolongation by CPZ on lidocaine durations. CPZ or ZD7288 alone did not produce typical regional anesthetic effects. Increased intracellular concentration of CAMP reversed the inhibition of CPZ on $I_{\mathrm{h}}$. Although $\mathrm{CPZ}$ alone inhibited $I_{\mathrm{Na}}$ at the concentration more than $30 \mu \mathrm{M}$, it did not inhibit the CAP amplitudes in isolated sciatic nerves. CPZ dose-dependently enhanced the inhibitory effect of $1 \%$ lidocaine on the CAP amplitudes.

Conclusions: CPZ may prolong durations of lidocaine in peripheral nerve block by modulation of HCN channel currents. 
Title: Capsazepine prolongation of the duration of lidocaine block of sensory transmission in mice may be mediated by modulation of HCN channel currents

Running title: Capsazepine prolongs regional anesthesia

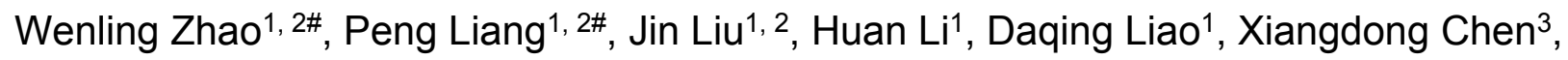
Qian $\mathrm{Li}^{1,2 *}$, Cheng Zhou ${ }^{1,2 *}$

${ }^{1}$ Laboratory of Anesthesia \& Critical Care Medicine, Translational Neuroscience Center, West China Hospital of Sichuan University, Chengdu, Sichuan, China;

2Department of Anesthesiology, West China Hospital of Sichuan University, Chengdu, Sichuan, China;

${ }^{3}$ Department of Anesthesiology, Union Hospital of Tongji Medical College, Huazhong University of Science and Technology, Wuhan, Hubei, China.

\#These authors contributed equally.

\section{${ }^{*}$ Address correspondence to:}

Dr. Cheng Zhou and Dr. Qian Li

Laboratory of Anesthesia \& Critical Care Medicine, Translational Neuroscience Center and Department of Anesthesiology, West China Hospital of Sichuan University, Chengdu, Sichuan, China

E-mail to: zhouc@163.com; hxliqian@foxmail.com 


\section{ABSTRACT}

1 Background and Objectives: Hyperpolarization-activation cyclic nucleotide-gated

2 (HCN) channels contribute to the effects of lidocaine. Capsazepine (CPZ), a competitive

3 inhibitor of capsaicin of transient receptor potential vanilloid-1 (TRPV-1) channel, has

4 also been found to inhibit $\mathrm{HCN}$ channel currents $\left(I_{h}\right)$. This study was designed to

5 investigate whether CPZ could prolong durations of lidocaine in regional anesthesia.

6 Methods: Mouse HCN1 and HCN2 channels were expressed in HEK 293 cells. The

7 effect of CPZ on $I_{\mathrm{h}}$ was measured by whole-cell patch-clamping recording. Sciatic nerve

8 block model in mice was used for the study in vivo. The mice were randomly divided into

97 groups, respectively receiving lidocaine, CPZ, ZD7288 (HCN channel blocker), CPZ +

10 lidocaine, ZD7288 + lidocaine, ZD7288 + CPZ + lidocaine, forskolin (an activator of

11 adenylyl cyclase) + CPZ + lidocaine. Regional anesthetic durations of lidocaine were

12 determined. Voltage-gated sodium channel currents $\left(I_{\mathrm{Na}}\right)$ and $I_{\mathrm{h}}$ were recorded in dorsal

13 root ganglion (DRG) neurons of mice. The effects of $\mathrm{CPZ}$ on $I_{\mathrm{Na}}$ and $I_{\mathrm{h}}$ with or without cAMP were assessed. Isolated mice sciatic nerve was prepared to evaluate the effect of CPZ on the compound action potentials (CAP).

Results: CPZ non-selectively inhibited transfected mHCN1 and $\mathrm{mHCN} 2$ channel currents in HEK 293 cells. In sciatic nerve block in vivo, compared to lidocaine alone, adding CPZ extended the durations of lidocaine for noxious sensory block (35.1 \pm 3.3 vs. $20.3 \pm 1.7 \mathrm{~min})$, tactile sensory block $(25.5 \pm 4.4$ vs. $20.0 \pm 3.7 \mathrm{~min})$, thermal sensory block (39.6 \pm 6.6 vs. $26.8 \pm 5.5 \mathrm{~min})$, and motor function block $(28.6 \pm 4.1$ vs. $20.9 \pm 4.2$ 
$21 \mathrm{~min}$ ). Duration of thermal sensory block was longer in CPZ + lidocaine group than that of

22 ZD7288 + lidocaine group $(39.6 \pm 6.6$ vs. $33.4 \pm 4.5 \mathrm{~min})$. Forskolin reversed the

23 prolongation by CPZ on lidocaine durations. CPZ or ZD7288 alone did not produce

24 typical regional anesthetic effects. Increased intracellular concentration of cAMP

25 reversed the inhibition of $\mathrm{CPZ}$ on $I_{\mathrm{h}}$. Although $\mathrm{CPZ}$ alone inhibited $I_{\mathrm{Na}}$ at the concentration

26 more than $30 \mu \mathrm{M}$, it did not inhibit the CAP amplitudes in isolated sciatic nerves. CPZ

27 dose-dependently enhanced the inhibitory effect of $1 \%$ lidocaine on the CAP amplitudes.

28 Conclusions: CPZ may prolong durations of lidocaine in peripheral nerve block by

29 modulation of $\mathrm{HCN}$ channel currents. 


\section{INTRODUCTION}

Although local anesthetics such as lidocaine have been widely used in clinic for over decades, there are still many disadvantages for currently used local anesthetics including toxicities and unsatisfied durations (Mather, 2010). To prolong the duration of local anesthetics, many adjuvants have been added in clinical regional anesthesia (Kirksey et al., 2015). However, the enhancement of most adjuvants are unsatisfied and some of the adjuvants can even induce unacceptable complications (Lundblad \& Lonnqvist, 2016).

Voltage-gated sodium channel is the principal molecular target for local anesthetics (Becker \& Reed, 2012). Recent studies have identified that hyperpolarization-activation cyclic nucleotide-gated $(\mathrm{HCN})$ channel might also contribute to the effects of local anesthetics in regional anesthesia (Meng et al., 2011; Zhou et al., 2015). HCN channel is a non-selective cation channel activated by hyperpolarization of membrane potential (Benarroch, 2013). HCN channel is the principal pacemaker for rhythmical regulator and determinant for resting membrane potential in nervous system and sinoatrial node for its distinct electrophysiological properties (Benarroch, 2013; Biel et al., 2009). HCN channel also plays an important role in neuropathic pain (Cao et al., 2016). Our previous study indicates that the duration of lidocaine is significantly shortened in HCN1 knockout mice (Zhou et al., 2015). Cyclic adenosine monophosphate (cAMP) is the enhancer for HCN channel currents $\left(I_{\mathrm{h}}\right)$ (Wainger et al. 2001). Increased level of cAMP by activator of adenylyl cyclase (e.g. forskolin) can shorten the durations of lidocaine in vivo (Kroin et al., 
52 2004; Zhou et al., 2015). By previous study, maximal inhibition of lidocaine on $I_{\mathrm{h}}$ is $\sim 50 \%$

53 (Meng et al., 2011). Therefore, adding more potent HCN channel modulators (e.g.

54 ZD7288, clonidine, and dexmedetomidine) to local anesthetics have been found to

55 extend the durations of lidocaine and ropivacaine in vivo (Brummett et al., 2011; Harris \&

56 Constanti, 1995; Kroin et al., 2004).

57 Capsazepine (CPZ) is a competitive inhibitor of capsaicin activation of transient receptor potential vanilloid-1 (TRPV-1) channel and has been reported as an emerging class of

59 novel analgesic (Menendez et al., 2006). TRPV-1 channel is mainly expressed on

60 nociceptor and involved in sensory processing (Cui et al., 2006). TRPV-1 channel can be

61 activated by high temperature, acid, capsaicin and other chemicals (Szallasi et al., 2007),

62 by which to trigger action potentials and release of neuropeptides and/or transmitters

63 (Cui et al., 2006; Peters et al., 2010). Therefore, TRPV-1 channel blocker might be

64 potent in the therapy of pain. CPZ has also been found to inhibit HCN channel currents

$65\left(I_{\mathrm{h}}\right)$ (Zuo et al., 2013).

66 In the present study, we hypothesized that CPZ, a potential adjuvant for local anesthetics,

67 might extend the durations of lidocaine by modulation of $\mathrm{HCN}$ channels. This study was designed to test this hypothesis. 


\section{METHODS}

\section{Animals}

Following the ARRIVE Guidelines and with the approval of the Institutional Animal Experimental Ethics Committee of Sichuan University (Chengdu, Sichuan, China, protocol 2015014A), sixty-three adult male C57BL/6J mice $(20-30 \mathrm{~g})$ for experiments of sciatic nerve block in vivo and in vitro and seven C57BL/6J mice at age of postnatal eight days for experiment of isolated DRG neurons were included. All the study mice were housed in standard condition with free access to food and water. All the mice were placed in the experimental environment for 1-2 hours per day for consecutive three days before the formal experiments. The observers of the behavioral test were blinded to the group assignment of the study mice.

\section{Chemicals}

Lidocaine solution was diluted from $2 \%(\mathrm{w} / \mathrm{v})$ lidocaine (Shanghai Fortune Zhaohui Pharmaceutical Co., Ltd., Shanghai, China) with normal saline to the final concentration of $1 \%(\mathrm{w} / \mathrm{v}, \sim 35 \mathrm{mM})$. ZD7288 (Tocris Bioscience, Bristol, UK), the non-selective HCN channel blocker, and forskolin (Sigma-Aldrich, Co., St. Louis, MO, US), the activator of adenylyl cyclase, were dissolved with normal saline. CPZ (Sigma-Aldrich, Co., St. Louis, MO, US) was dissolved with DMSO (Sigma-Aldrich, Co., St. Louis, MO, US) to a 2.5 $\mathrm{mg} / \mathrm{mL}$ stock solution and then diluted with normal saline (for animal study in vivo) or bath solution (for electrophysiological recordings) to the final concentrations. For 
91 electrophysiological recordings, the final concentration of DMSO was $0.05 \%(\mathrm{v} / \mathrm{v})$, which

92 produces minimal effect in electrophysiological recordings (Liu et al., 2016; Wang et al., 93 2016).

\section{Patch clamping recordings}

The vectors of pcDNA3-HE3 with mHCN1 (Mouse HCN1) and mHCN2 (Mouse HCN2) were expressed in HEK 293 (human embryonic kidney 293) cells as previously described (Gill et al., 2004). HEK 293 cells were cultured under standard procedures (Meng et al., 2011). The $\mathrm{mHCN}$ channel constructs were co-transfected with a green fluorescent protein plasmid (pEGFP; Clontech Laboratories, Mountain View, CA) by Lipofectamine 2000 reagent (Invitrogen, Carlsbad, CA). Recordings were performed 3648 hours after transfection. Whole-cell patch clamping recordings were performed at room temperature $\left(\sim 24-25^{\circ} \mathrm{C}\right)$. Patch pipettes (with resistance of 3-5 $\mathrm{M} \Omega$ ) were made from the fire-polished borosilicate glass capillaries (Sutter Instrument Co., Novato, Calif). $I_{\mathrm{h}}$ were sampled using an Axon 200B amplifier, digitized via a Digidata 1440A interface. Standard bath solution contained (mM) $118 \mathrm{NaCl}, 25 \mathrm{KCl}, 2 \mathrm{MgCl}_{2}, 2 \mathrm{CaCl}_{2}, 10 \mathrm{HEPES}$, and 10 glucose, $\mathrm{pH}=7.4$ adjusted by $\mathrm{NaOH}$. Bath solution was continuously perfused at speed of $\sim 2 \mathrm{~mL} / \mathrm{min}$. Pipette solution contained (mM) $120 \mathrm{KCH}_{4} \mathrm{SO}_{3}, 4 \mathrm{NaCl}, 1 \mathrm{MgCl}_{2}$,

$\mathrm{KOH}$ (Meng et al., 2011). 
111 Hyperpolarization-activated currents $\left(I_{\mathrm{h}}\right)$ were evoked by hyperpolarized pulses (4 s)

112 from $-40 \mathrm{mV}$ to $-130 \mathrm{mV}$ with interval of $-10 \mathrm{mV}$ (Gill et al., 2004). Amplitudes of steady-

113 state currents were produced at the end of hyperpolarizing voltage steps as tail currents,

114 which used for the analysis of voltage dependence of channel gating. Tail currents were

115 acquired at a fixed potential of $-90 \mathrm{mV}$ immediately after hyperpolarized pulses and

116 were normalized and fitted with Boltzmann curves as: $G / G_{\max }=1 /\left(1+e\left(V_{1 / 2 a}-V\right) / k\right)$,

117 where $\mathrm{G} / \mathrm{G}_{\max }=$ normalized conductance; $\mathrm{G}_{\max }=$ maximum conductance; $\mathrm{V}_{1 / 2 \mathrm{a}}=$ voltage

118 of half-maximumactivation; $\mathrm{k}=$ slope factor. Concentration-response of CPZ on the $I_{\mathrm{h}}$

119 was fitted to the Hill equation: $Y=1 /\left[1+10\left(\log I C_{50}-X\right)^{\star} h\right]$, where $Y=$ inhibitory ratio; $X$

$120=$ concentration of $\mathrm{CPZ} ; \mathrm{h}=$ Hill coefficient.

121 Acute isolated dorsal root ganglion (DRG) neurons were prepared for recordings of

122 sodium channel currents $\left(I_{\mathrm{Na}}\right)$ and $I_{\mathrm{h}}$. Briefly, mice were anesthetized by

123 ketamine/xylazine $(40 / 15 \mathrm{mg} / \mathrm{kg})$. Then the DRGs of mice were removed and digested

124 respectively in $1 \%$ papain for $45 \mathrm{~min}$ and in $1 \%$ collagenase I for $30 \mathrm{~min}$. DRG neurons

125 were recorded after 2-h cell attachment to the coverslip. $I_{\mathrm{h}}$ was evoked by hyperpolarized

126 pulse $(4 \mathrm{~s})$ to $-120 \mathrm{mV}$ with the same solutions used for recordings on HEK 293 cells. To

127 test the effect of intracellular cAMP, $200 \mu \mathrm{M}$ cAMP was added to the patch pipette. $I_{\mathrm{Na}}$

128 was recorded by depolarized pulse $(20 \mathrm{~ms})$ to $10 \mathrm{mV}$. Bath solution contained (in $\mathrm{mM})$ :

$129125 \mathrm{NaCl}, 25 \mathrm{NaHCO}_{3}, 1.25 \mathrm{NaH}_{2} \mathrm{PO}_{4}, 2.5 \mathrm{KCl}, 1 \mathrm{MgCl}_{2}, 2 \mathrm{CaCl}_{2}, 15$ glucose, 25 TEA-

$130 \mathrm{Cl}$. Internal solution contained (in mM): $110 \mathrm{CsF}, 9 \mathrm{NaCl}, 1.8 \mathrm{MgCl}_{2}, 4 \mathrm{Mg}-\mathrm{ATP}, 0.3 \mathrm{Na}-$ 
131 GTP, 0.09 EGTA, $0.018 \mathrm{CaCl}_{2}, 9 \mathrm{HEPES}, 10 \mathrm{TEA}-\mathrm{Cl}$. CsOH was used to adjust to $\mathrm{pH}=$

7.35 (290-310 mOsm).

\section{Sciatic nerve block model}

Anesthetized with $2 \%$ isoflurane (Abbott Pharmaceutical Co. Ltd. Shanghai, China), total volume of $50 \mu \mathrm{L}$ study solution was injected into the popliteal fossa of the mice and the needle was removed $5 \mathrm{~s}$ after injection. The injected site was then pressed for at least 5 $s$ to prevent exudation of study solution. Fifty-six mice were randomly divided into 7 groups ( $\mathrm{n}=8 /$ group): respectively receiving lidocaine alone, CPZ alone, ZD7288 (HCN channel blocker) alone, CPZ + lidocaine, ZD7288 + lidocaine, ZD7288 + CPZ + lidocaine, forskolin (an activator of adenylyl cyclase) + CPZ + lidocaine. The concentrations of lidocaine, ZD7288, CPZ and forskolin were 1\% (w/v, 35 mM), $5 \mathrm{mM}, 53 \mu \mathrm{M}$ and $153 \mu \mathrm{M}$, respectively (Kroin et al., 2004; Zuo et al., 2013). For the groups that received two or three drugs, ZD7288 and/or forskolin were injected 20 min before lidocaine and CPZ was injected 10 min before lidocaine (Ando et al., 2004; Kroin et al., 2004).

After the mice recovered to consciousness ( $\sim$ min after injection), a 25-G needle 147 (Terumo Medical Corp., Tokyo, Japan) tied to a plastic fiber ( $3 \mathrm{~g}$ equivalent to the vonfrey fiber) was used to evaluate noxious sensory function of the injected limb. Noxious sensory block was defined as no purposeful aversive movements to the pinprick stimulus. Von-frey filaments (37450-277; Ugo Basile, Comerio, Italy) was used to test tactile sensation of the injected limb and tactile sensory block was defined as no purposeful 
152 reactions to increased von-frey fibers more than $2 \mathrm{~g}$ compared to baselines. The specific

153 site for application of pinprick and von-frey fiber was lateral plantar surfaces innervated

154 by sciatic nerve. Thermal sensory function was determined by heat stimulus (Plantar test

155 37370; Ugo Basile, intensity of infrared radiation set at 60) applied to the injected limb.

156 Thermal sensory block was defined as the withdraw latency of the mice increased more

157 than $50 \%$ of the baseline latency (Becker \& Reed, 2012). Cut-off time of thermal stimulus

158 was $10 \mathrm{~s}$ to avoid injury. Motor function of mice was evaluated by the ability of hanging

159 upside down with the injected paws (Yamada et al., 2016). Before injection, baselines of

160 each function were measured. Because TRPV-1 channel blockers have been reported to

161 induce dysregulation of body temperature (Yang et al., 2015), rectal temperature of the

162 study mice was observed. For all the studied mice, rectal temperatures were normal (36-

$16338^{\circ} \mathrm{C}$ ) during the regional anesthesia. All the mice completely recovered from regional

164 anesthesia without any adverse events.

165

166 Compound action potential (CAP) recording on isolated sciatic nerves

167 Adult C57BL/6J mice were used. Bilateral sciatic nerves were obtained from the lumbar

168 plexus to the knee. Then the sciatic nerves were put into a Ringer's solution (115.5 mM

$169 \mathrm{NaCl}, 2 \mathrm{mM} \mathrm{KCl}, 1.8 \mathrm{mM} \mathrm{CaCl}_{2}, 1.3 \mathrm{mM} \mathrm{Na}_{2} \mathrm{HPO}_{4}$ and $0.7 \mathrm{mM} \mathrm{NaH}_{2} \mathrm{PO}_{4}, \mathrm{pH}=7.35$ ) for

17020 min. BL-420N biological signal acquisition and analysis system (Techman Software

171 Co. LTD, Chengdu, China) was used. Baseline values of CAPs were recorded every 5

172 min until 20 min to obtain a stable baseline. Then, the CAPs of each group were 
173 obtained after the sciatic nerve incubating into the drug solutions for $5 \mathrm{~min}$. The 174 parameters of the system were set as: voltage $=1 \mathrm{~V}$; frequency $=100 \mathrm{~Hz}$; duration of 175 rectangular pulse $=0.1 \mathrm{~ms}($ Li et al., 2010).

177 Statistical analysis

SPSS 22.0 (SPSS Inc., Chicago, IL, US) was used to analyze the data. The sample size 179 ( $n=8 /$ group) of the animal study in vivo was based on our preliminary test $(n=4$, not included in formal data). The duration of lidocaine for noxious sensory block was compared between the groups of lidocaine alone and lidocaine + CPZ (20.5 vs. 30.5 $\min )$. Then the sample size was calculated as $5.0(\alpha=0.05 ; \beta=0.20)$. Duration data were calculated by averaging the duration of each mouse in the same group and expressed as mean \pm SEM. The homogeneity of variance tests indicated that the duration data were normal distributed. One-way analysis of variance (ANOVA) followed by post hoc of Bonferroni was applied to compare the durations between groups. Kaplan-Meier followed by pair-wise over strata of Log-rank was applied to compare the recovery curves of motor function block and noxious sensory block. For the results of electrophysiological recordings, all the data were presented as mean \pm SEM. Voltagedependent activation curves of $I_{\mathrm{h}}$ were fit to the Boltzmann equation. Two-way ANOVA or student's t-test was applied to compare $I_{\mathrm{h}}$ and channel gating as indicated. In all cases, 192 $P<.05$ was considered as statistically significant. 
194

195

196

197

198

199

200

201

202

203

204

205

206

207

208

209

210

211

212

213

214

\section{RESULTS}

CPZ inhibited transfected $\mathrm{mHCN}$ channel currents and hyperpolarized voltagedependent activation

CPZ at concentration of $10 \mu \mathrm{M}$ potently inhibited I-V curves of both mHCN1 and mHCN2 channels (Fig. 1). $I_{50}$ (median inhibitory concentration) of $\mathrm{CPZ}$ on peak $I_{\mathrm{h}}$ were $8.2 \pm 0.3$ $\mu \mathrm{M}$ and $9.6 \pm 0.4 \mu \mathrm{M}$, respectively for $\mathrm{mHCN} 1$ and $\mathrm{mHCN} 2(P>.05$, Fig. 2$)$. CPZ at concentration of $10 \mu \mathrm{M}$ significantly caused a hyperpolarizing shift in voltagedependence of channel activation for both $\mathrm{mHCN} 1\left(\mathrm{~V}_{1 / 2 \mathrm{a}}\right.$ of $-98.4 \pm 3.8 \mathrm{vs} .-88.6 \pm 3.6$ $\mathrm{mV}, P<.01$, Fig. 3$)$ and $\mathrm{mHCN} 2\left(\mathrm{~V}_{1 / 2 \mathrm{a}}\right.$ of $-102.7 \pm 13.5 \mathrm{mV}$ vs. $-114.6 \pm 12.9 \mathrm{mV}, P<$ .01, Fig. 3).

\section{CPZ prolonged duration of lidocaine in sciatic nerve block model in vivo}

ZD7288 alone (5 mM) did not produce any sciatic nerve block in vivo. CPZ alone (53 $\mu \mathrm{M})$ produced thermal sensory block with duration of $24.6 \pm 2.7 \min$ (Table 1). Compared with lidocaine alone, adding ZD7288 prolonged durations of lidocaine including noxious sensory block (34.3 \pm 5.2 vs. $20.3 \pm 1.7 \mathrm{~min}, P<.001$, Fig. $4 a)$, tactile sensory block (25.0 \pm 4.3 vs. $20.0 \pm 3.7 \mathrm{~min}, P=.036$, Fig. $4 \mathrm{~b})$, thermal sensory block $(33.4 \pm 4.5$ vs $26.8 \pm 5.5 \mathrm{~min}, P=.027$, Fig. 4c) and motor function block $(27.9 \pm 4.3$ vs. $20.9 \pm 4.2 \mathrm{~min}$ $P=.008$, Fig. 4d). Compared with ZD7288 + lidocaine group, CPZ similarly extended the durations of lidocaine including noxious sensory block, tactile sensory block and motor block. For noxious sensory block, CPZ prolonged the duration from $20.3 \pm 1.7$ to $35.1 \pm$ 
$2153.3 \mathrm{~min}(P<.001$ vs. lidocaine alone, Fig. 4a). For tactile sensory block, CPZ prolonged

216 the duration from $20.0 \pm 3.7$ to $25.5 \pm 4.4 \mathrm{~min}(P=.025$ vs. lidocaine alone, Fig. $4 \mathrm{~b})$. For

217 motor function block, $\mathrm{CPZ}$ prolonged the duration from $20.9 \pm 4.2$ to $28.6 \pm 4.1 \mathrm{~min}(P=$

218.003 vs. lidocaine alone, Fig. 4d). For thermal sensory block, CPZ + lidocaine group was

219 significantly longer than that of ZD7288 + lidocaine group $(39.6 \pm 6.6$ vs. $33.4 \pm 4.5 \mathrm{~min}$,

$220 P=.017$, Fig. 4c). Adding ZD7288 and CPZ to lidocaine (ZD7288 + CPZ + Lido group)

221 did not further prolong the duration of lidocaine for noxious sensory block compared to

222 ZD7288 + Lido group or CPZ + Lido group (Fig. 4a). Of note, the durations of tactile

223 sensory block, thermal sensory block and motor block in ZD7288 + CPZ + Lido group

224 were not determined because slight sedation was found in some mice, which might

225 affect accuracy of the results. The pinprick stimulus (puncturing the skin by a $25-\mathrm{G}$

226 needle) was much stronger than other stimulus like von-frey and in the manner of "all or

227 none" compared with other quantitative measurements (e.g. von-frey and heat). No

228 redness or swelling was found in the test limb during the whole experiment. All mice

229 recovered completely after regional anesthesia. The time courses of all the regional

230 anesthetic effects were shown in Fig. 5.

\section{Pre-injection of forskolin reversed the prolongation of CPZ in regional anesthesia}

233 Pre-injection of forskolin $(153 \mu \mathrm{M})$ diminished the prolongation of CPZ on durations of 234 lidocaine (Fig. 4 and Fig. 5). The anesthetic durations were shorter in Forskolin + CPZ + 235 Lido group than that in CPZ + Lido group including noxious sensory block (35.1 \pm 3.3 vs. 
$23618.9 \pm 3.0 \mathrm{~min}, P<.001$, Fig. 4 a), tactile sensory block $(25.5 \pm 4.4$ vs. $18.5 \pm 5.0 \mathrm{~min}, P=$

237.015 , Fig. 4b), thermal sensory blockade $(39.6 \pm 6.6$ vs. $24.8 \pm 5.2 \mathrm{~min}, P<.001$, Fig. $4 \mathrm{c})$

238 and motor blockade $(28.6 \pm 4.1$ vs. $19.5 \pm 3.0 \mathrm{~min}, P=.001$, Fig. $4 \mathrm{~d})$. All the data were

239 shown in Table 1. Of note, pre-injection of forskolin was prone to shorten the durations of

240 lidocaine compared with lidocaine alone group, indicating the contribution of HCN

241 channels in the effects of lidocaine (Fig. 5a, b, d).

cAMP reversed the inhibitory effect of $\mathrm{CPZ}$ on $I_{\mathrm{h}}$ in DRG neurons

244 The average current density of $I_{\mathrm{h}}$ was $2.3 \pm 0.4 \mathrm{pA} / \mathrm{pF}$ in control condition, while 245 intracellular cAMP at $200 \mu \mathrm{M}$ significantly increased the current density of $I_{\mathrm{h}}$ to $7.6 \pm 2.3$ $246 \mathrm{pA} / \mathrm{pF}\left(P<.05\right.$, Fig. 6b). CPZ at concentration of $10 \mu \mathrm{M}$ inhibited $I_{\mathrm{h}}$ density to $1.9 \pm 0.7$ $247 \mathrm{pA} / \mathrm{pF}$. Intracellular cAMP at $200 \mu \mathrm{M}$ reversed $I_{\mathrm{h}}$ density to $7.1 \pm 1.6 \mathrm{pA} / \mathrm{pF}$ even with 248 perfusion of $10 \mu \mathrm{M} \mathrm{CPZ}(P<.05$, Fig. 6d).

CPZ enhanced inhibition of lidocaine on action potential in sciatic nerves

$251 \mathrm{CPZ}$ at concentration of $10 \mu \mathrm{M}$ did not inhibit $/_{\mathrm{Na}}$ in isolated mice DRG neurons (Fig. 7a), 252 while $30 \mu \mathrm{M} \mathrm{CPZ}$ significantly inhibited the current density of $I_{\mathrm{Na}}$ from $105.9 \pm 23.3 \mathrm{pA} / \mathrm{pF}$ 253 to $68.2 \pm 20.3 \mathrm{pA} / \mathrm{pF}(P<.05$, Fig. $7 \mathrm{c})$. However, neither $10 \mu \mathrm{M}$ nor $30 \mu \mathrm{M}$ CPZ inhibited 254 the CAP amplitudes in isolated sciatic nerves compared to baseline (Fig. 7e-h). The CAP 255 amplitudes were inhibited by $43.3 \% \pm 1.5 \%$ after incubation in $1 \%$ lidocaine for $5 \mathrm{~min}$. CPZ dose-dependently enhanced the inhibitory effect of $1 \%$ lidocaine on the CAP. For $1 \%$ 
257 lidocaine $+10 \mu \mathrm{M} \mathrm{CPZ}$ group and/or $1 \%$ lidocaine $+30 \mu \mathrm{M} \mathrm{CPZ}$ group, the CAP 258 amplitudes were decreased to $20.5 \% \pm 3.0 \%$ and/or $12.6 \% \pm 0.8 \%$ compared to baseline, 259 respectively $(P<.01$ vs. $1 \%$ lidocaine, Fig. $7 \mathrm{i})$.

260 


\section{DISCUSSION}

263 Long-lasting local anesthetics are demanded in clinic especially for post-operative

264

265

266

267

268

269

270

271

272

273

274

275

276

277

278

279

280

281

282

analgesia and treatment of chronic pain. To prolong duration of local anesthetics and reduce their toxicities, many adjuvants have been added to local anesthetics (YilmazRastoder et al., 2012). The adjuvants for local anesthetics mainly include epinephrine, ketamine, opioids and NSAIDs (Bailard et al., 2014). However, the enhancement of most adjuvants are unsatisfied and some adjuvants can even induce unacceptable side effects themselves, such as poor selectivity, undesired systematic sedation or thermal irritation (Brummett \& Williams, 2011). In the present study, CPZ significantly extended the durations of lidocaine for sciatic nerve block without obvious complications. Therefore, CPZ may be a potential adjuvant for local anesthetics.

CPZ is a competitive inhibitor of capsaicin activation of TRPV-1 channel (Yang et al., 2015). At micromolar concentrations, CPZ can also block voltage-dependent potassium channel, calcium channel and sodium channel (Kuenzi et al., 1996; Yamamura et al., 2004; Lundbaek et al., 2005). In the present study, to test whether voltage-gated sodium channels are involved in the enhancement of CPZ on regional anesthesia of lidocaine in vivo, acute DRG neurons and isolated sciatic nerves were used for recordings of $I_{\mathrm{Na}}$ and CAP, respectively. CPZ alone at concentration of $30 \mu \mathrm{M}$ indeed inhibited $I_{\mathrm{Na}}$ in $\mathrm{DRG}$ neurons. However, CPZ did not affect amplitudes and/or conductions of CAP in isolated sciatic nerves at concentration of $30 \mu \mathrm{M}$. Previous study indicates that inhibition of CPZ on $I_{\mathrm{Na}}$ is possibly by altering lipid bilayer elasticity of the cellular membrane (Lundbaek et 
al., 2005). Therefore, the differential results of CPZ between voltage-gated $I_{\mathrm{Na}}$ and action

284 potential might result from the myelin sheath around nerves that preventing direct

285 exposure of CPZ to cellular membrane. In spite of no effect was found for CPZ alone on

286 CAP, it can enhance the inhibitory effect of lidocaine on CAP amplitudes since the

287 concentration of $10 \mu \mathrm{M}$. Consistent with the observation in vivo, CPZ alone did not

produce typical sciatic nerve block, but prolonged the durations of lidocaine. Although

CPZ may not inhibit action potential alone by inhibition to sodium channels, it cannot

completely exclude the possible contribution of sodium channel block by CPZ for its

enhancement in regional anesthesia. Even a small additional inhibition of sodium

channel might prolong the effects of lidocaine.

293

CPZ can inhibit transfected human HCN channel currents (Zuo et al., 2013). HCN

channel is widely expressed in peripheral nervous system (Acosta et al., 2012; Cao et al.,

2016). HCN channels may contribute to the regional anesthetic effects of lidocaine in

296 vivo, both for the sensory and motor function block (Zhou et al., 2015). By

297 electrophysiological recordings, lidocaine was found to inhibit $I_{\mathrm{h}}$ (Meng et al., 2011).

298 However, lidocaine at clinical concentrations only inhibits $I_{\mathrm{h}}$ by $\sim 30 \%-50 \%$ (Meng et al.,

299 2011). Thus potent HCN channel blocker might enhance effects of local anesthetics

300 (Brummett et al., 2011). HCN channel modulators (e.g. ZD7288, clonidine and

dexmedetomidine) have been found to enhance regional anesthetic effects of lidocaine

and/or ropivacaine in vivo (Brummett et al., 2011; Harris \& Constanti, 1995; Kroin et al.,

2004). Although CPZ can inhibit transfected human HCN channel currents (Zuo et al., 
304

305

306

307

308

309

310

311

312

313

314

315

316

317

318

319

320

321

322

323

324

2013), it is unclear whether CPZ can enhance regional anesthesia in vivo. In the present study, CPZ inhibits transfected mice $\mathrm{HCN}$ channel currents without selectivity between $\mathrm{HCN} 1$ and $\mathrm{HCN} 2$. The $\mathrm{IC}_{50}$ of $\mathrm{CPZ}$ measured in this study $(\sim 10 \mu \mathrm{M})$ is similar to the potency on human $I_{\mathrm{h}}$ (Gill et al., 2004; Zuo et al., 2013), indicating the enhancement of CPZ for regional anesthesia might be conserved between species.

ZD7288 and CPZ similarly prolong the durations of lidocaine. Adding both ZD7288 and CPZ to lidocaine did not further prolong the duration of noxious sensory block compared with ZD7288 + Lido or CPZ + Lido group. Therefore, enhancement of ZD7288 and CPZ in regional anesthesia might be both mediated through modulation of $I_{\mathrm{h}}$. For DRG neurons, intracellular cAMP reversed the inhibitory effect of CPZ on $I_{h}$. The enhancement by CPZ for lidocaine in sciatic nerve block was eliminated by pre-injection of forskolin. Forskolin can increase the intracellular level of cAMP (Brummett et al., 2011) and is widely used to enhance $I_{\mathrm{h}}$ (Wainger et al., 2001; Kroin et al., 2004). These results provide better evidence to support the hypothesis that modulation of $\mathrm{CPZ}$ on $I_{\mathrm{h}}$ may contribute to its enhancement in regional anesthesia. Forskolin will also likely increase local blood flow and enhance drug clearance. However, the concentration of forskolin used in this study was $153 \mu \mathrm{M}$, which is lower than the blood concentration $(\sim 400 \mu \mathrm{M})$ to influence the blood flow (Wysham et al., 1986). Forskolin reversed the prolongation of capsazepine most potently in von-frey test than pin-prick test, foot-thermal test and motor function evaluation (Figure 5); thus the selective effect of forskolin might not be explained by increasing the blood flow (no selectivity). Interestingly, the enhancement of 
cAMP between HCN1 and HCN2 is different (Wainger et al., 2001), which might

contribute to the differential reversion by forskolin between different functions.

CPZ alone can produce thermal sensory block without lidocaine. The thermal sensory

block duration in CPZ + lidocaine group is longer than that of ZD7288 + lidocaine group.

The selective enhancement of $\mathrm{CPZ}$ for thermal sensory might result from the inhibition of

TRPV-1 channels. TRPV-1 channel blocker is potential treatment for various types of

pain (Walker et al., 2003). However, because of the role of TRPV-1 channel as

temperature sensor, systemic administration of TRPV-1 channel blocker can induce

serious hyperpyrexia (Menendez et al., 2006), which limits the clinical application of

TRPV-1 channel blocker. The systemic dosage of CPZ to induce hyperpyrexia is unknown, but other TRPV-1 antagonists such as AMG517, GRC6211 and NGD8243

have been dropped out of clinical trials due to hyperpyrexia (Pareek et al., 2007). In this

study, CPZ is perineurally injected and no obvious change was found for mice body temperature.

There are some limitations in the present study: Firstly, forskolin, an activator of adenylyl cyclase, is not a selective agonist of $\mathrm{HCN}$ channels. Forskolin can increase the level of cAMP, which is an enhancer of HCN channels (Wainger et al., 2001; Kroin et al., 2004).

Secondly, ZD7288 and CPZ are non-selective blocker between HCN1 and HCN2 subtypes. Thus, we cannot evaluate the specific role of $\mathrm{HCN} 1$ and $\mathrm{HCN} 2$. Further studies with HCN selective blockers such as MEL57A and/or EC18 might shed light on this question (DelLungo et al., 2012). In addition, potential effect of CPZ on HCN4 
346 (cardiac subtype) should be tested further to explore potential influence of CPZ on heart.

347 Co-injection of vasoconstrictor and CPZ may not only prolong the durations of local

348 anesthetics, but also reduce the systemic impact of CPZ in regional anesthesia.

349

\section{CONCLUSIONS}

351 In summary, CPZ, a widely known competitive inhibitor of capsaicin activation of TRPV-1

352 channel, can inhibit $I_{\mathrm{h}}$ and prolong durations of lidocaine in vivo. The enhancement of

$353 \mathrm{CPZ}$ in regional anesthesia may be mediated by modulation of $I_{\mathrm{h}}$. Therefore, CPZ is a

354 potential regional anesthetic adjuvant in clinic. 
356

357

358

359

360

361

362

363

364

365

366

367

368

369

370

371

372

373

374

375

376

\section{REFRENCES}

Acosta C, McMullan S, Djouhri L, Gao L, Watkins R, Berry C, Dempsey K, and Lawson SN. 2012. HCN1 and HCN2 in Rat DRG neurons: levels in nociceptors and non-nociceptors, NT3-dependence and influence of CFA-induced skin inflammation on HCN2 and NT3 expression. PLoS One 7:e50442. DOI 10.1371/journal.pone.0050442

Ando R, Yonezawa A, Watanabe C, and Kawamura S. 2004. An assessment of vascular pain using the flexor reflex in anesthetized rats. Methods Find Exp Clin Pharmacol 26:109-115.

Bailard NS, Ortiz J, and Flores RA. 2014. Additives to local anesthetics for peripheral nerve blocks: Evidence, limitations, and recommendations. Am J Health Syst Pharm 71:373-385. DOI 10.2146/ajhp130336

Becker DE, and Reed KL. 2012. Local anesthetics: review of pharmacological considerations. Anesth Prog 59:90-101; quiz 102-103. DOI 10.2344/0003-300659.2 .90

Benarroch EE. 2013. HCN channels: function and clinical implications. Neurology 80:304-310. DOI 10.1212/WNL.0b013e31827dec42

Biel M, Wahl-Schott C, Michalakis S, and Zong X. 2009. Hyperpolarization-activated cation channels: from genes to function. Physiol Rev 89:847-885. DOI 10.1152/physrev.00029.2008

Brummett CM, Hong EK, Janda AM, Amodeo FS, and Lydic R. 2011. Perineural 
dexmedetomidine added to ropivacaine for sciatic nerve block in rats prolongs the duration of analgesia by blocking the hyperpolarization-activated cation current. Anesthesiology 115:836-843. DOI 10.1097/ALN.0b013e318221fcc9

Brummett CM, and Williams BA. 2011. Additives to local anesthetics for peripheral nerve blockade. Int Anesthesiol Clin 49:104-116. DOI 10.1097/AIA.0b013e31820e4a49

Cao Y, Pang J, and Zhou P. 2016. HCN Channel as Therapeutic Targets for Heart Failure and Pain. Curr Top Med Chem 16:1855-1861.

Cui M, Honore P, Zhong C, Gauvin D, Mikusa J, Hernandez G, Chandran P, Gomtsyan A, Brown B, Bayburt EK, Marsh K, Bianchi B, McDonald H, Niforatos W, Neelands TR, Moreland RB, Decker MW, Lee CH, Sullivan JP, and Faltynek CR. 2006. TRPV1 receptors in the CNS play a key role in broadspectrum analgesia of TRPV1 antagonists. J Neurosci 26:9385-9393. DOI 10.1523/jneurosci.1246-06.2006

Del Lungo M, Melchiorre M, Guandalini L, Sartiani L, Mugelli A, Koncz I, Szel T, Varro A, Romanelli MN, and Cerbai E. 2012. Novel blockers of hyperpolarization-activated current with isoform selectivity in recombinant cells and native tissue. $\mathrm{Br} J$ Pharmacol 166:602-616. DOI 10.1111/j.14765381.2011.01782.x

Gill CH, Randall A, Bates SA, Hill K, Owen D, Larkman PM, Cairns W, Yusaf SP, Murdock PR, Strijbos PJ, Powell AJ, Benham CD, and Davies CH. 2004. 
Characterization of the human HCN1 channel and its inhibition by capsazepine.

Br J Pharmacol 143:411-421. DOI 10.1038/sj.bjp.0705945

400

401

402

403

404

405

406

407

408

409

410

411

412

413

414

415

416

417

418

Harris NC, and Constanti A. 1995. Mechanism of block by ZD 7288 of the hyperpolarization-activated inward rectifying current in guinea pig substantianigra neurons in vitro. J Neurophysiol 74:2366-2378. DOI 10.1152/jn.1995.74.6.2366

Kirksey MA, Haskins SC, Cheng J, and Liu SS. 2015. Local Anesthetic Peripheral Nerve Block Adjuvants for Prolongation of Analgesia: A Systematic Qualitative Review. PLoS One 10:e0137312. DOI 10.1371/journal.pone.0137312

Kroin JS, Buvanendran A, Beck DR, Topic JE, Watts DE, and Tuman KJ. 2004. Clonidine prolongation of lidocaine analgesia after sciatic nerve block in rats Is mediated via the hyperpolarization-activated cation current, not by alphaadrenoreceptors. Anesthesiology 101:488-494.

Kuenzi FM and Dale N. 1996. Effect of capsaicin and analogues on potassium and calcium currents and vanilloid receptors in Xenopus embryo spinal neurones. $\mathrm{Br} \mathrm{J}$ Pharmacol 119:81-90

Li Z, Yang J, Liu J, Gong CY, Gan J, Zhang X, Luo WJ and Li GH. 2010. Reversible conduction block in isolated toad sciatic nerve by emulsified isoflurane. Anesth Analg 110:1024-1029. DOI:10.1213/ANE.0b013e3181d2732f

Liu H, Yang L, Chen KH, Sun HY, Jin MW, Xiao GS, Wang Y and Li GR. 2016. SKF96365 blocks human ether-a-go-go-related gene potassium channels stably expressed in HEK 293 cells. Pharmacol Res 104:61-69. 
420

421

422

423

424

425

426

427

428

429

430

431

432

433

434

435

436

437

438

439

Lundbaek JA, Birn P, Tape SE, Toombes GE, Søgaard R, Koeppe RE 2nd, Gruner SM, Hansen AJandAndersen OS. 2005. Capsaicin regulates voltage-dependent sodium channels by altering lipid bilayer elasticity. Mol Pharmacol 68:680-689. DOI10.1124/mol.105.013573

Lundblad M, and Lonnqvist PA. 2016. Adjunct analgesic drugs to local anaesthetics for neuroaxial blocks in children. Curr Opin Anaesthesiol 29:626-631. DOI 10.1097/aco.0000000000000372

Mather LE. 2010. The acute toxicity of local anesthetics. Expert Opin Drug MetabToxicol 6:1313-1332. DOI 10.1517/17425255.2010.514265

Menendez L, Juarez L, Garcia E, Garcia-Suarez O, Hidalgo A, and Baamonde A. 2006. Analgesic effects of capsazepine and resiniferatoxin on bone cancer pain in mice. Neurosci Lett 393:70-73. DOI 10.1016/j.neulet.2005.09.046

Meng QT, Xia ZY, Liu J, Bayliss DA, and Chen X. 2011. Local anesthetic inhibits hyperpolarization-activated cationic currents. Mol Pharmacol 79:866-873. DOI 10.1124/mol.110.070227

Pareek TK, Keller J, Kesavapany S, Agarwal N, Kuner R, Pant HC, ladarola MJ, Brady RO, and Kulkarni AB. 2007. Cyclin-dependent kinase 5 modulates nociceptive signaling through direct phosphorylation of transient receptor potential vanilloid 1. Proc Natl Acad Sci $U$ S A 104:660-665. DOI 10.1073/pnas.0609916104 
440

441

442

443

444

445

446

447

448

449

450

451

452

453

454

455

456

457

458

459

460

Peters JH, McDougall SJ, Fawley JA, Smith SM, and Andresen MC. 2010. Primary afferent activation of thermosensitive TRPV1 triggers asynchronous glutamate release at central neurons. Neuron 65:657-669. DOI 10.1016/j.neuron.2010.02.017

Szallasi A, Cortright DN, Blum CA, and Eid SR. 2007. The vanilloid receptor TRPV1: 10 years from channel cloning to antagonist proof-of-concept. Nat Rev Drug Discov 6:357-372. DOI 10.1038/nrd2280

Wainger BJ, DeGennaro M, Santoro B, Siegelbaum SA and Tibbs GR. 2001. Molecular mechanism of cAMP modulation of HCN pacemaker channels. Nature 411:805-10. DOI10.1038/35081088

Walker KM, Urban L, Medhurst SJ, Patel S, Panesar M, Fox AJ, and McIntyre P. 2003. The VR1 antagonist capsazepine reverses mechanical hyperalgesia in models of inflammatory and neuropathic pain. J Pharmacol Exp Ther 304:56-62. DOI 10.1124/jpet.102.042010

Wang H, Wang HF, Wang C, Chen YF, Ma R, Xiang JZ, Du XL and Tang Q. 2016. Inhibitory effects of hesperetin on Kv1.5 potassium channels stably expressed in HEK 293 cells and ultra-rapid delayed rectifier $\mathrm{K}(+)$ current in human atrial myocytes. Eur J Pharmacol 789:98-108. DOI10.1016/j.ejphar.2016.07.015

Wysham DG, Brotherton AF and Heistad DD. 1986. Effects of forskolin on cerebral blood flow: implications for a role of adenylate cyclase. Stroke 17:1299-303.

Yamada T, Hasegawa-Moriyama M, Kurimoto T, Saito T, Kuwaki T, and Kanmura Y. 
461

462

463

464

465

466

467

468

469

470

471

472

473

474

475

476

477

478

479

480

481

2016. Peripheral Nerve Block Facilitates Acute Inflammatory Responses Induced by Surgical Incision in Mice. Reg Anesth Pain Med 41:593-600. DOI 10.1097/aap.0000000000000458

Yamamura H, Ugawa S, Ueda T, Nagao M and Shimada S. 2004. Capsazepine is a novel activator of the delta subunit of the human epithelial $\mathrm{Na}+$ channel. $J$ Biol Chem 279:44483-9. DOI 10.1074/jbc.M408929200

Yang S, Yang F, Wei N, Hong J, Li B, Luo L, Rong M, Yarov-Yarovoy V, Zheng J, Wang K, and Lai R. 2015. A pain-inducing centipede toxin targets the heat activation machinery of nociceptor TRPV1. Nat Commun 6:8297. DOI 10.1038/ncomms9297

Yilmaz-Rastoder E, Gold MS, Hough KA, Gebhart GF, and Williams BA. 2012. Effect of adjuvant drugs on the action of local anesthetics in isolated rat sciatic nerves. Reg Anesth Pain Med37:403-409. DOI 10.1097/AAP.0b013e3182485965

Zhou C, Ke B, Zhao Y, Liang P, Liao D, Li T, Liu J, and Chen X. 2015. Hyperpolarization-activated cyclic nucleotide-gated channels may contribute to regional anesthetic effects of lidocaine. Anesthesiology 122:606-618. DOI 10.1097/aln.0000000000000557

Zuo GF, Li MH, Zhang JX, Li B, Wang ZM, Wang Q, Xiao H, and Chen SL. 2013. Capsazepine concentration dependently inhibits currents in HEK 293 cells mediated by human hyperpolarization-activated cyclic nucleotide-gated 2 and 4 channels. Exp Biol Med (Maywood) 238:1055-1061. DOI 
Table $\mathbf{1}$ (on next page)

Durations of sciatic nerve block for each group. 
TABLE 1. Durations of sciatic nerve block for each group

\begin{tabular}{lllll}
\hline \multirow{2}{*}{ Groups } & \multicolumn{3}{c}{ Durations (min) } \\
\cline { 2 - 5 } ZD7288 & Pin-Prick & Von-frey & Thermal & Motor \\
\cline { 2 - 5 } CPZ & N/A & N/A & N/A & N/A \\
Lido & N/A & N/A & $24.6 \pm 2.7$ & N/A \\
ZD7288 + Lido & $20.3 \pm 1.7$ & $20.0 \pm 3.7$ & $26.8 \pm 5.5$ & $20.9 \pm 4.2$ \\
CPZ + Lido & $34.3 \pm 5.2^{*}$ & $25.0 \pm 4.3^{*}$ & $33.4 \pm 4.5^{*}$ & $27.9 \pm 4.3^{*}$ \\
Forskolin + CPZ + Lido & $18.9 \pm 3.0^{\#}$ & $18.5 \pm 5.0^{\#}$ & $24.8 \pm 5.2^{\#}$ & $19.5 \pm 3.0^{\#}$ \\
ZD7288 + CPZ + Lido & $32.5 \pm 7.9$ & N/D & N/D & N/D \\
\hline
\end{tabular}

Data were expressed as mean \pm SEM $(n=8 /$ group $)$.

*: $P<.05$ vs. Lido group; †: $P<.05$ vs. ZD7288 + Lido group; \#: $P<.05$ vs. CPZ + Lido group; Lido: 1\% lidocaine; CPZ: capsazepine; N/A: no action; N/D: not determined. 


\section{Figure 1}

CPZ inhibited HCN channel currents expressed on HEK 293 cells.

a: CPZ inhibited HCN1 and HCN2 channel currents. b: Effect of CPZ on I-V curves of HCN1 and HCN2 channels. Hyperpolarizing voltage steps from -40 to $-130 \mathrm{mV}$ evoked the currents of mHCN1 and mHCN2 channels. CPZ at $10 \mu \mathrm{M}$ depressed the currents. Voltage steps were followed by a step to $-90 \mathrm{mV}$ for tail current analysis. CPZ effectively shifted voltagedependent activation of HCN1 and HCN2 channels in a hyperpolarized direction. CPZ: capsazepine; $*: P<.05$ vs. control group. Sample size $=5 \sim 6$.

a

$\mathrm{HCN} 1$

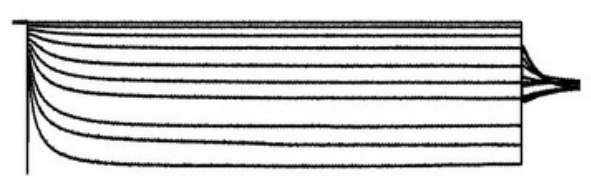

$\mathrm{HCN} 2$

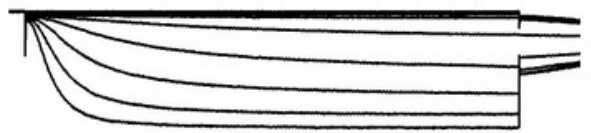

b Membrane potential (mV)

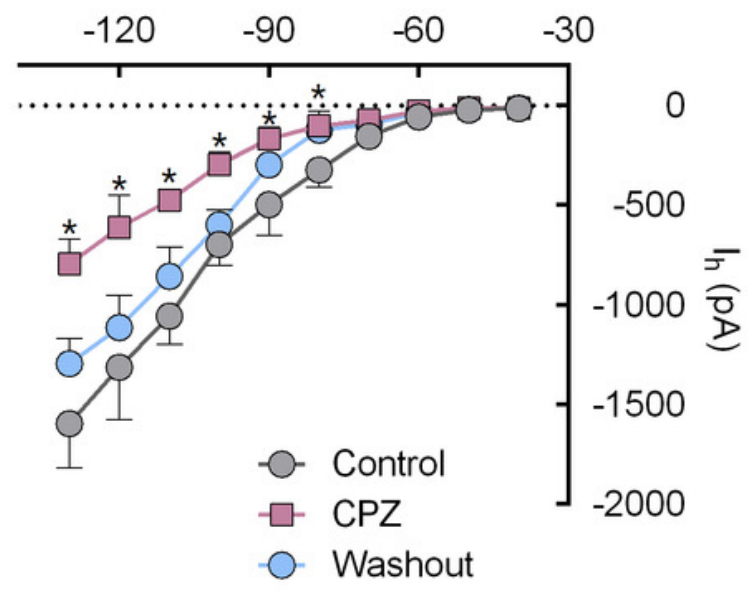

HCN1
CPZ

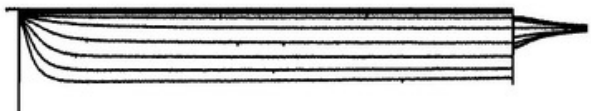

$1 \mathrm{nA}$

$500 \mathrm{~ms}$

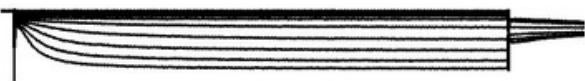

Membrane potential $(\mathrm{mV})$

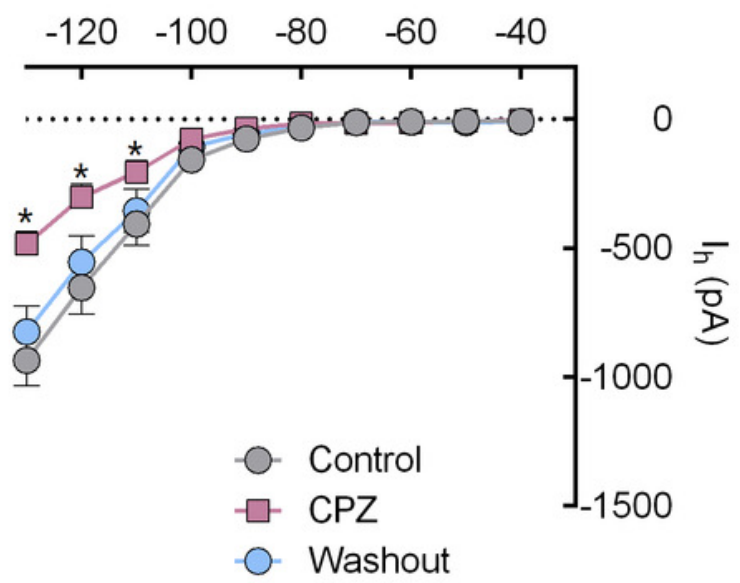

$\mathrm{HCN} 2$ 
Figure 2

CPZ concentration-dependently inhibited HCN1 (๑) and HCN2 (ם) channel currents.

The inhibitory potency of CPZ on HCN channel currents is similar between HCN1 and HCN2 channels, with $\mathrm{IC}_{50}$ of $9.6 \pm 0.4$ and $8.2 \pm 0.3 \mu \mathrm{M}$ for HCN1 and HCN2, respectively. CPZ: capsazepine. Sample size $=6$. 


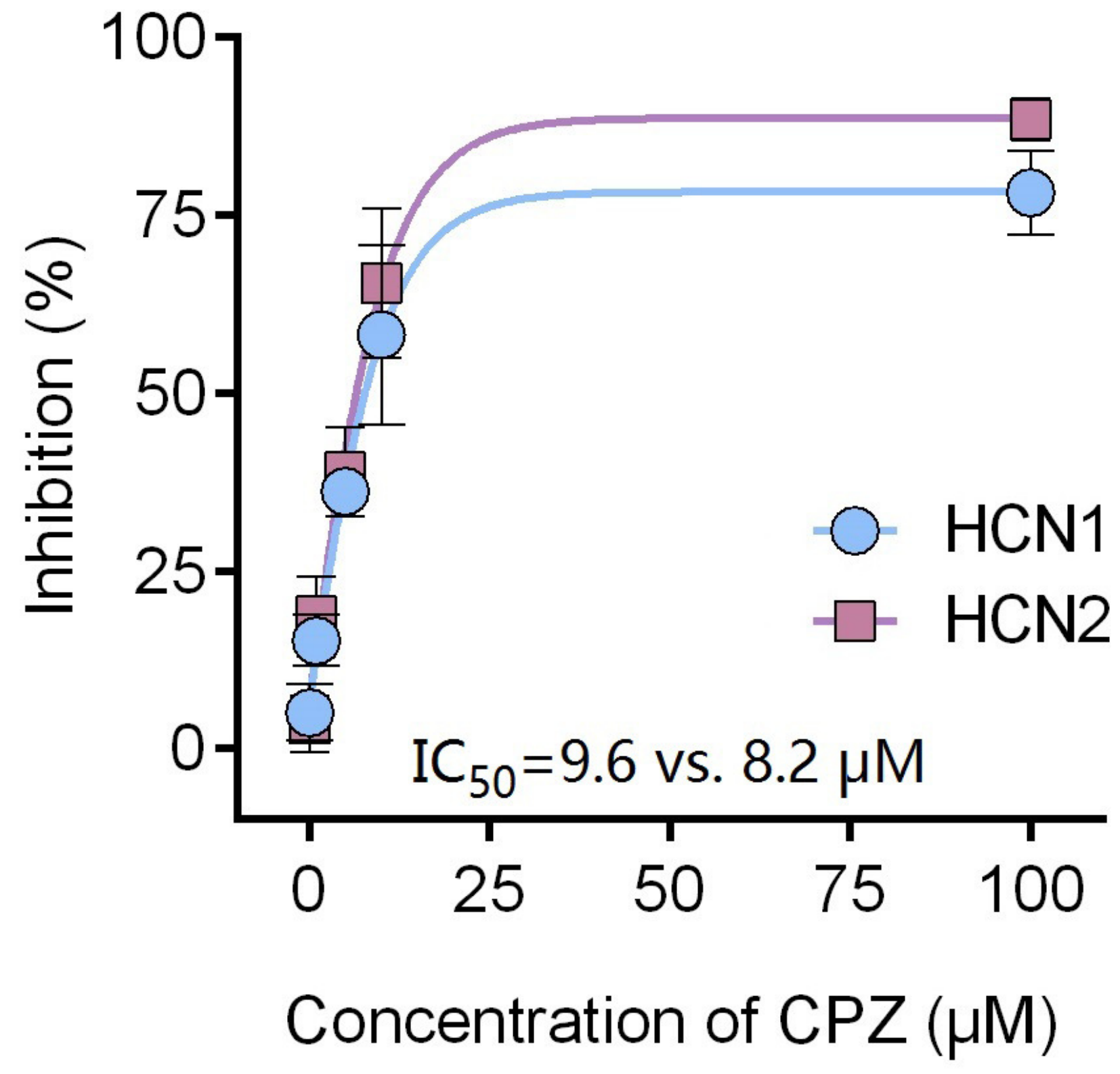




\section{Figure 3}

Voltage-dependent activation curves of HCN1 and HCN2 channels.

a: Voltage-dependent activation curve of HCN1 channel. b: Voltage-dependent activation curve of HCN2 channel. CPZ significantly hyperpolarized the voltage-dependent activation of HCN1 and HCN2 channels. CPZ (10 $\mu \mathrm{M})$ caused a hyperpolarizing shift in voltage-dependence of $\mathrm{V}_{1 / 2 \text { act }}$ from $-89.8 \pm 2.6$ to $-99.2 \pm 3.6 \mathrm{mV}(* P<.01)$ and from $-103.8 \pm 2.9$ to $-114.1 \pm$ $4.8 \mathrm{mV}(* P<.01)$, respectively for HCN1 and HCN2 channel. The voltage-dependent activation curves were based on tail currents. CPZ: capsazepine. Sample size $=7$.
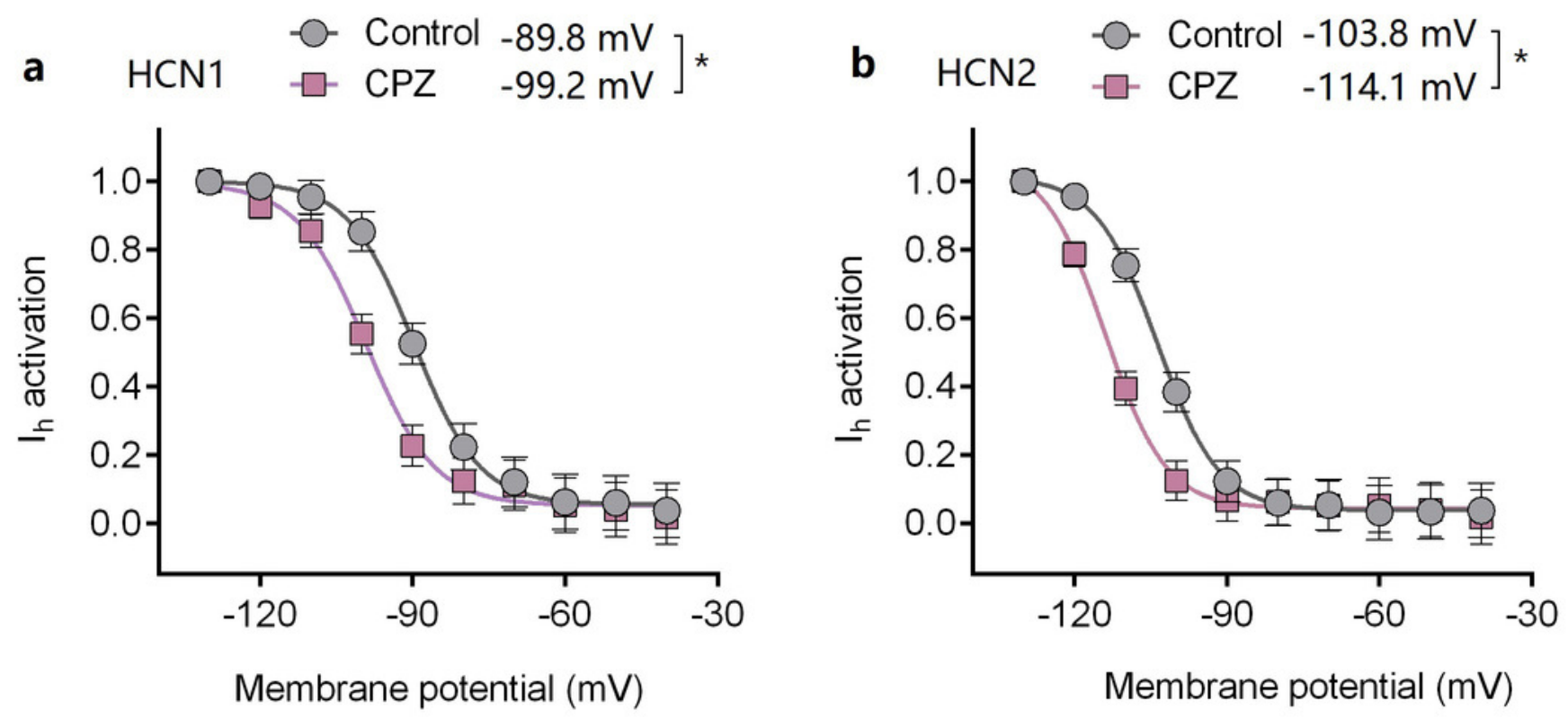


\section{Figure 4}

Durations of sciatic nerve block produced by different drug combinations.

a: Pin-prick test; b: Von-frey test; c: Foot-thermal test; d: Motor function evaluation. Regional anesthetic durations of CPZ + Lido group and ZD7288 + Lido group were significantly longer than lido alone group, while forskolin reversed the prolongation by CPZ. In pin-prick test (a), ZD7288 + CPZ + Lido group did not produce any longer block than neither CPZ + Lido group nor ZD7288 + Lido group. For foot-thermal test (c), block duration of CPZ + Lido group was significantly longer than ZD7288 + Lido group. CPZ: capsazepine; Lido: lidocaine; *: $P<.05$

vs. Lido alone group; $* *: P<.01$ vs. Lido alone group; ${ }^{* \#}: P<.01$ vs. $C P Z+$ Lido group. Sample size $=8$. 
a

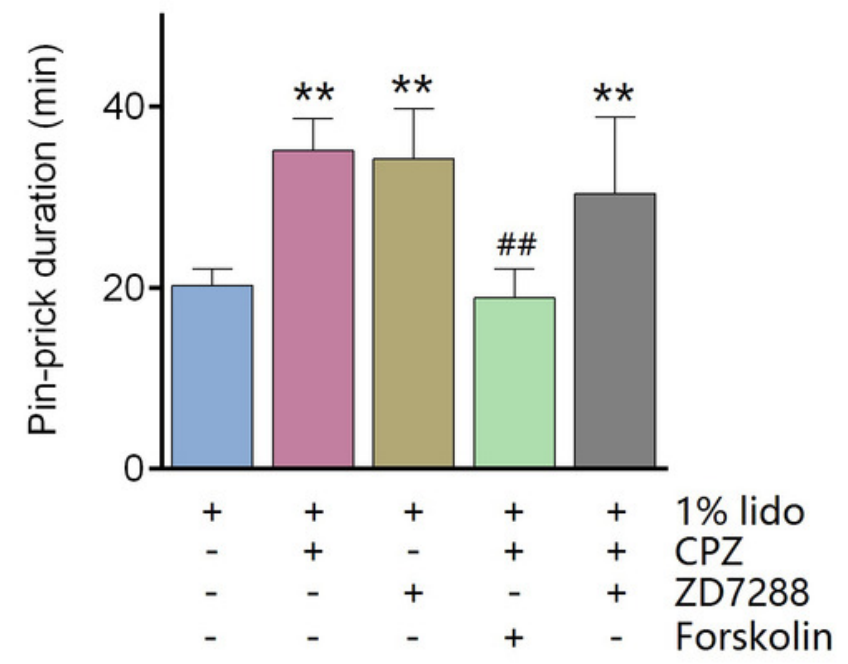

b

d

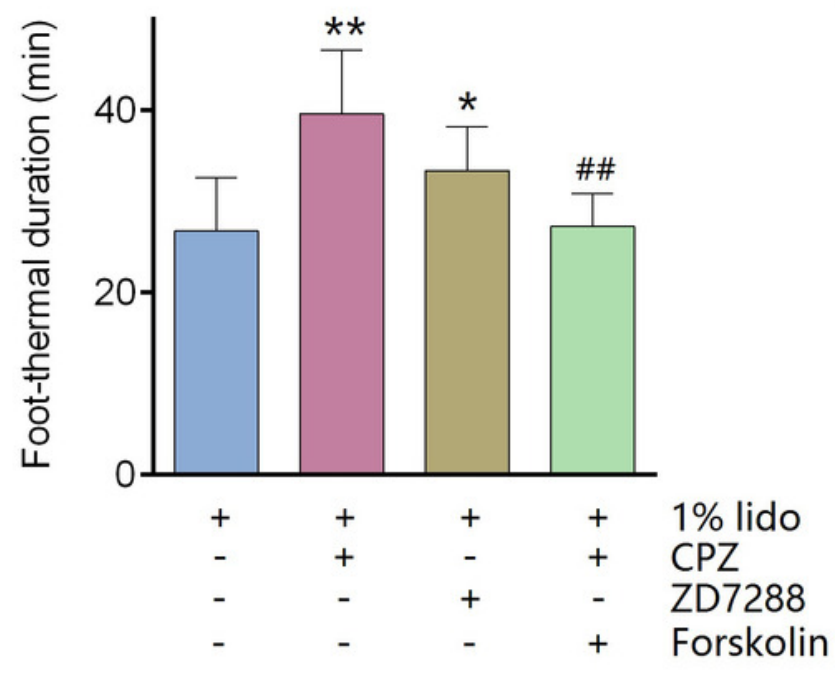

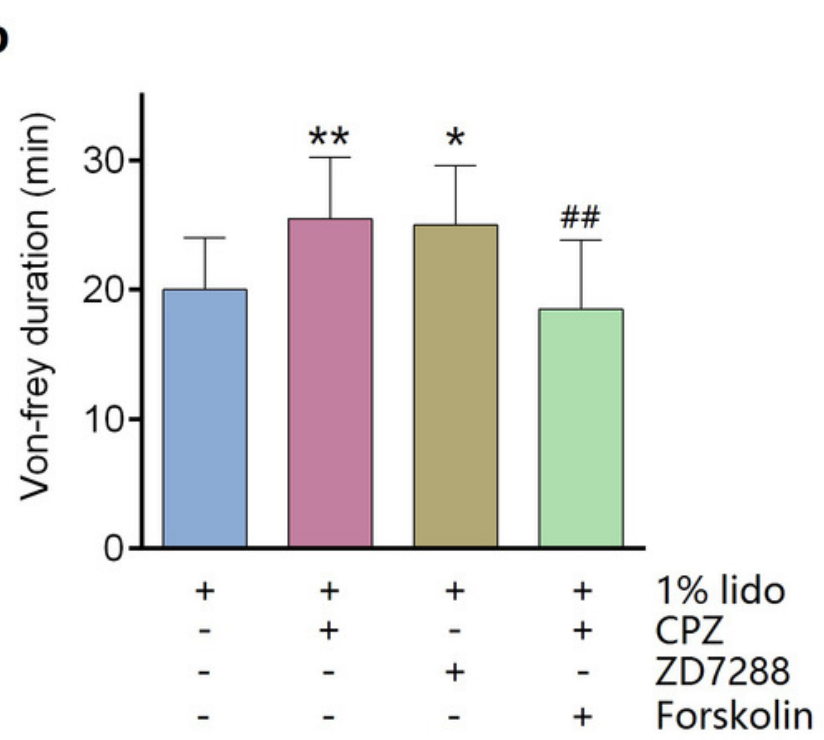

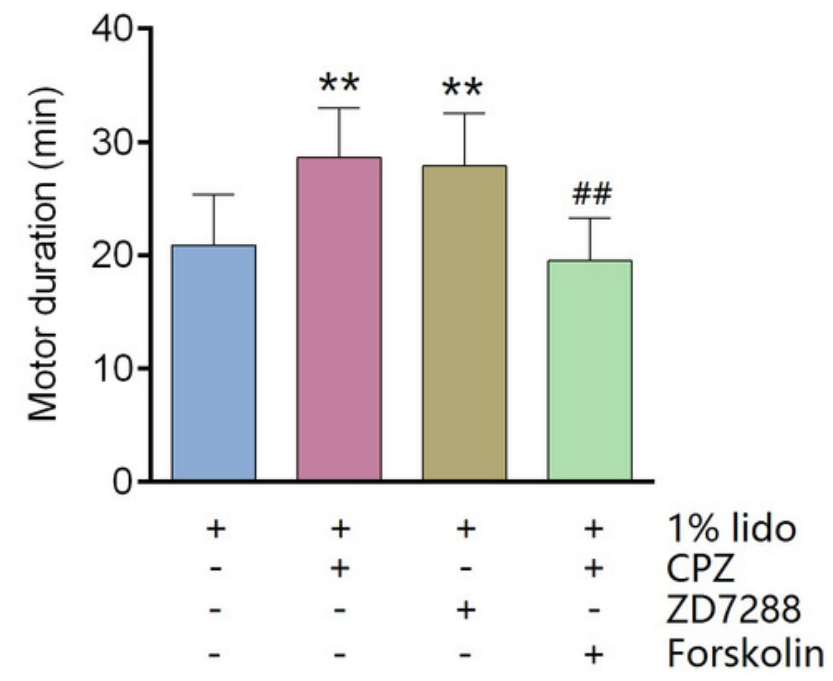




\section{Figure 5}

Onset and recovery of regional anesthetic effects by different tests.

a: Pin-prick test; b: Von-frey test; c: Foot-thermal test; d: Motor function evaluation. For pinprick test (a) and motor function evaluation (d), the time-dependent curves indicate block percentage at each time point. For von-frey test (b) and foot-thermal test (c), the timedependent curves were calculated by averaging the results at each time point. CPZ: capsazepine; Lido: lidocaine; $*: P<.05$ vs. Lido alone group. Sample size $=8$.

a

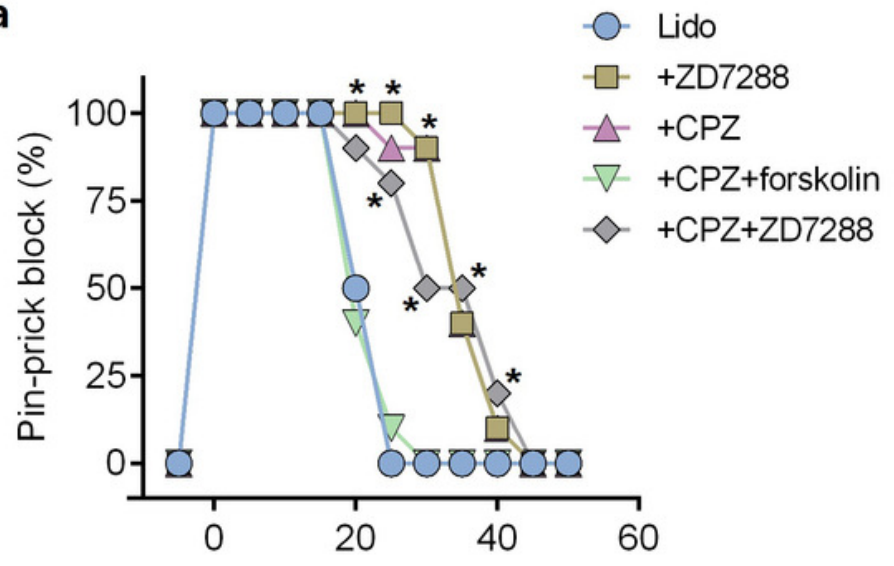

Time (min)

C

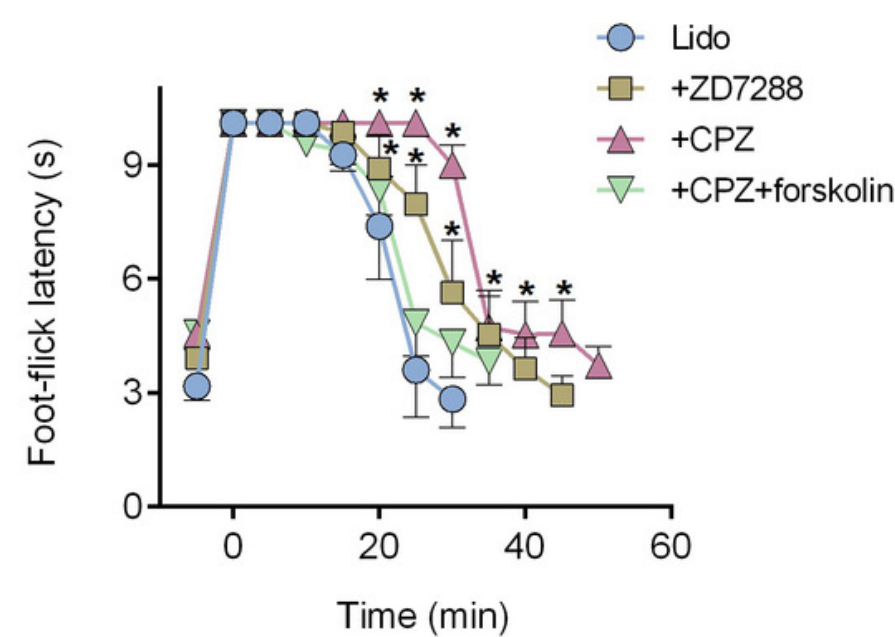

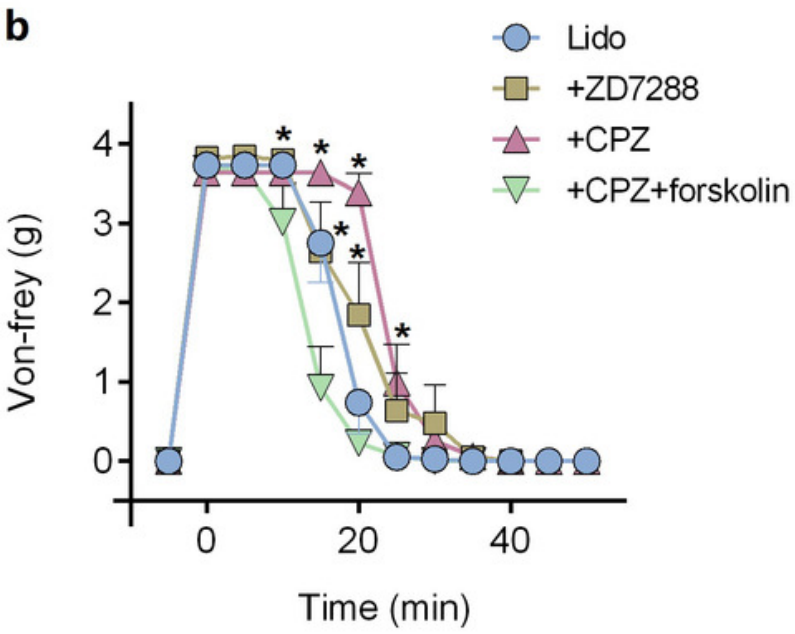

d

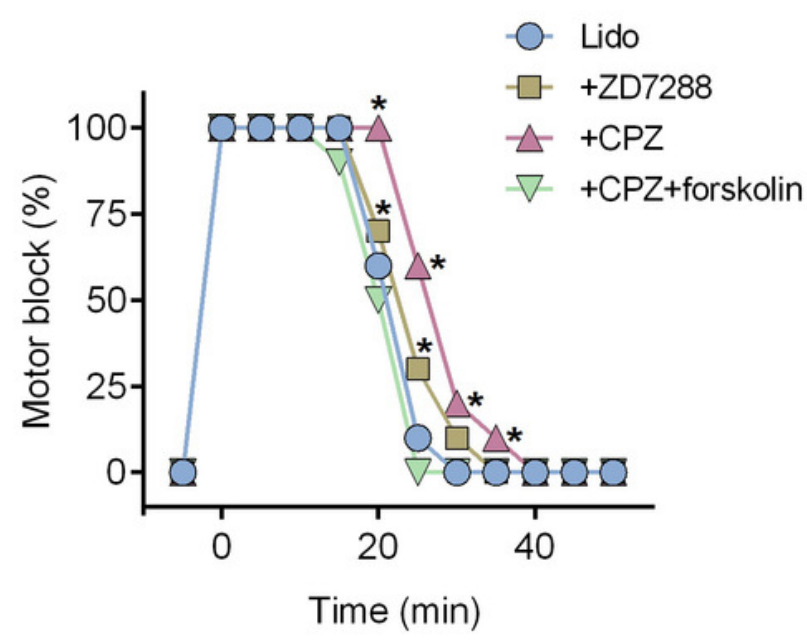




\section{Figure 6}

Increased intracellular CAMP reversed the inhibitory effect of CPZ on HCN channel currents $\left(I_{h}\right)$ in mice DRG neurons.

a: Representative traces of the $I_{h}$ activated by $200 \mu$ M cAMP. b: Current density of $I_{h}$ in DRG neurons of mice significantly increased from $2.3 \pm 0.4 \mathrm{pA} / \mathrm{pF}$ to $7.6 \pm 2.3 \mathrm{pA} / \mathrm{pF}$ when cAMP $(200 \mu \mathrm{M})$ was introduced to the cytoplasm from the patch pipette. C: Representative $I_{\mathrm{h}}$ traces when CPZ $(10 \mu \mathrm{M})$ added with and without CAMP. d: CPZ inhibited $I_{\mathrm{h}}$ density in mice DRG neurons to $1.9 \pm 0.7 \mathrm{pA} / \mathrm{pF}$, while cAMP reversed to $7.1 \pm 1.6 \mathrm{pA} / \mathrm{pF}$. CPZ: capsazepine; DRG: dorsal root ganglion; $*: P<.05$. Sample size $=8-12$. 
a

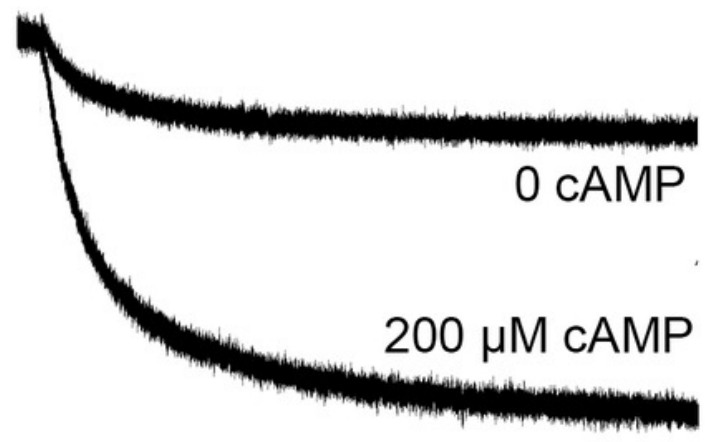

b

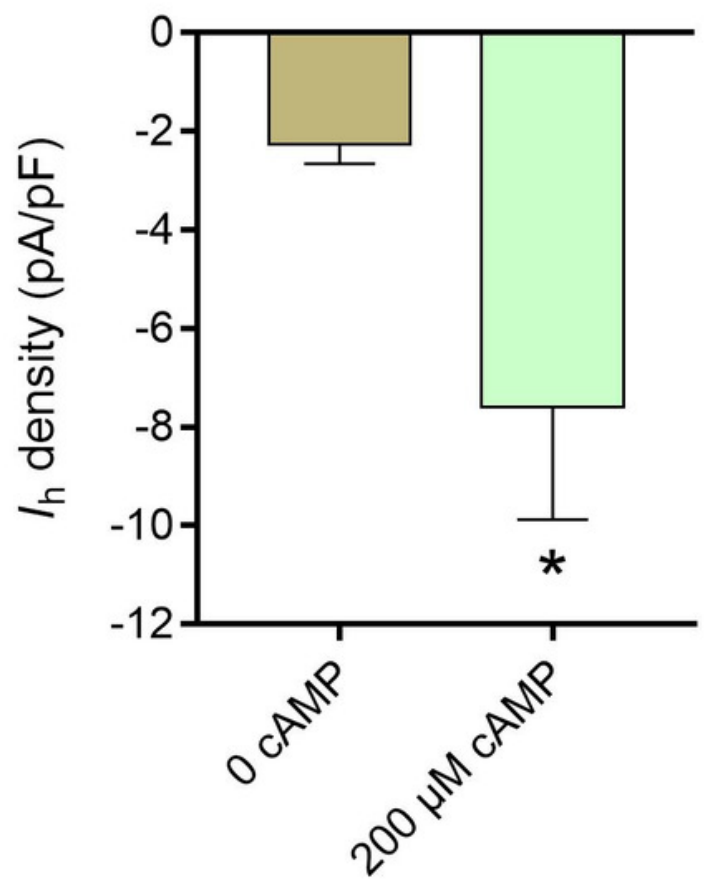

C

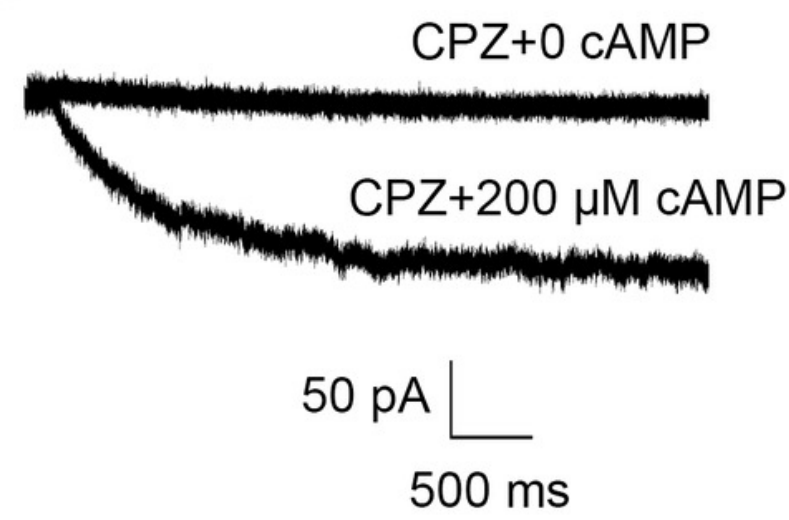

d

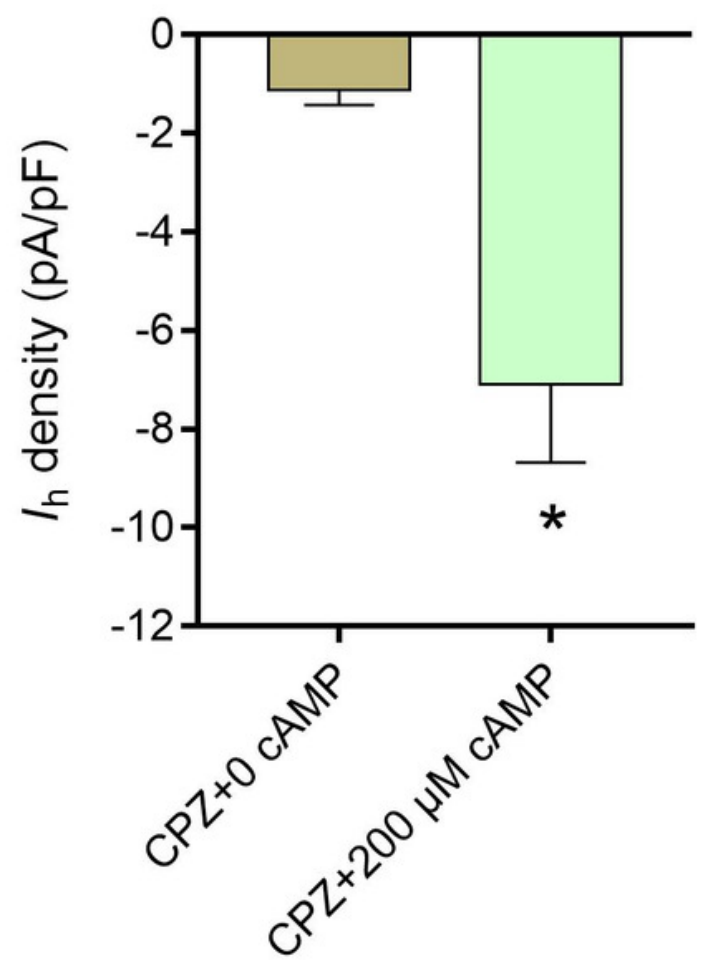




\section{Figure 7}

The effects of CPZ on voltage-gated sodium channel current $\left(I_{\text {Na }}\right)$ in DRG neurons and compound action potentials (CAP) amplitudes in sciatic nerves of mice.

a-d: CPZ at $10 \mu \mathrm{M}$ showed no influence on $I_{\text {Na }}($ a), while $30 \mu \mathrm{M} C P Z$ significantly inhibited current density of $I_{\mathrm{Na}}(\mathrm{c})$. The rightmost traces $(\mathrm{b}, \mathrm{d})$ show samples of $I_{\mathrm{Na}}$ after perfusion of 10 $\mu \mathrm{M}$ and $30 \mu \mathrm{M} C P Z$, respectively. e-h: CPZ at $10 \mu \mathrm{M}$ or $30 \mu \mathrm{M}$ did not inhibit CAP amplitudes in mice sciatic nerves. Samples (f, h) are shown in the right. i: CPZ at $10 \mu \mathrm{M}$ and/or $30 \mu \mathrm{M}$ enhanced the inhibitory effect of $1 \%$ lidocaine on CAP amplitudes. $j$ are the representative traces. CPZ: capsazepine; DRG: dorsal root ganglion; CAP: compound action potentials; $*: P<$ .05 vs. control group; **: $P<.01$ vs. $1 \%$ lidocaine group; ${ }^{\# \#}: P<.01$ vs. $1 \%$ lidocaine $+10 \mu \mathrm{M}$ CPZ group. Sample size $=3-5$. 

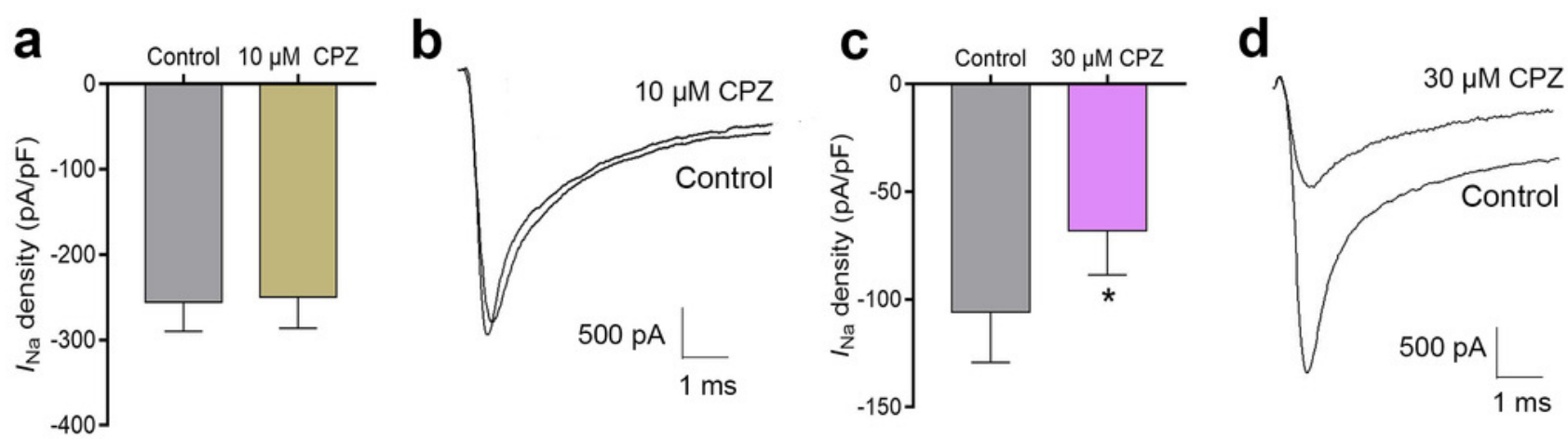

e
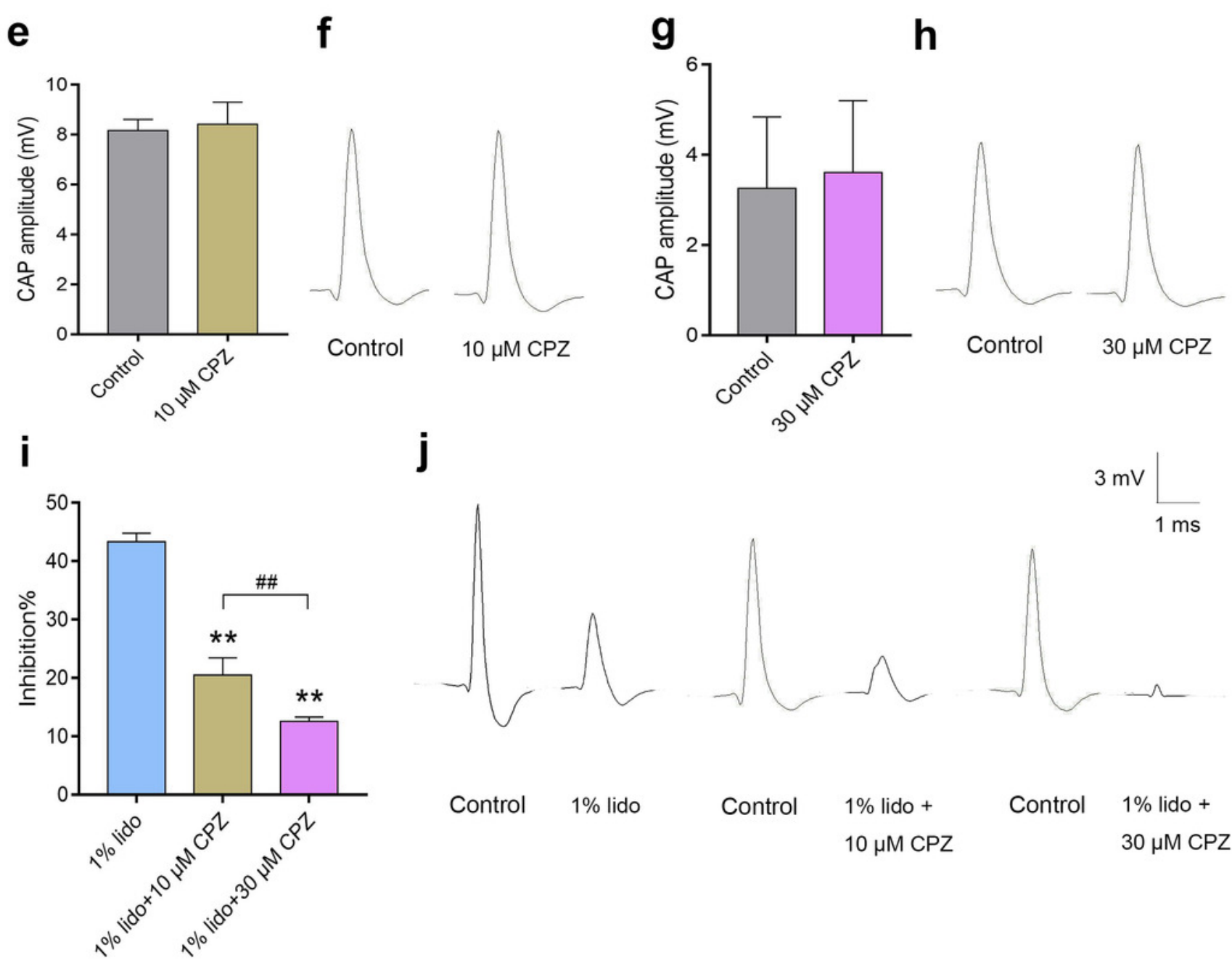

j
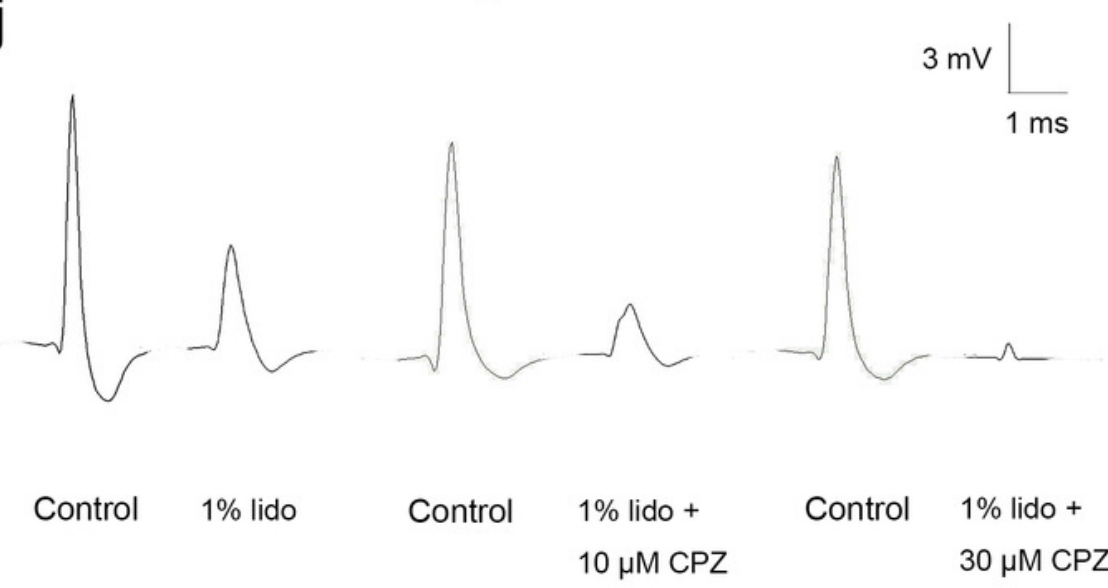
Control $1 \%$ lido + $30 \mu \mathrm{M} \mathrm{CPZ}$

